Primary decompressive craniectomy is associated with worse neurological outcome in patients with traumatic brain injury requiring acute surgery

Tapper, Julius

2017-07-11

Tapper , J , Skrifvars , M B , Kivisaari , R , Siironen , J \& Raj , R 2017 , ' Primary decompressive craniectomy is associated with worse neurological outcome in patients with traumatic brain injury requiring acute surgery ' , Surgical Neurology International , vol. 8 , 141 . https://doi.org/10.4103/sni.sni_453_16

http://hdl.handle.net/10138/232115

https://doi.org/10.4103/sni.sni_453_16

publishedVersion

Downloaded from Helda, University of Helsinki institutional repository.

This is an electronic reprint of the original article.

This reprint may differ from the original in pagination and typographic detail.

Please cite the original version. 


\title{
Primary decompressive craniectomy is associated with worse neurological outcome in patients with traumatic brain injury requiring acute surgery
}

\author{
Julius Tapper, Markus B. Skrifvars',2, Riku Kivisaari, Jari Siironen, Rahul Raj \\ Department of Neurosurgery, Helsinki University Hospital and University of Helsinki, ${ }^{1}$ Department of Anesthesiology, Intensive Care and Pain Medicine, Division \\ of Intensive Care, Helsinki University Hospital and University of Helsinki, Helsinki, Finland, ${ }^{2}$ Australian and New Zealand Intensive Research Centre, School of \\ Public Health and Preventive Medicine, Monash University, Melbourne, Australia \\ E-mail: Julius Tapper - julius.tapper@helsinki.fi; Markus B. Skrifvars - markus.skrifvars@hus.fi; Riku Kivisaari - riku.kivisaari@hus.fi; \\ Jari Siironen - jari.siironen@hus.fi; *Rahul Raj - rahul.raj@hus.fi \\ *Corresponding author
}

Received: 15 November $16 \quad$ Accepted: 06 March $17 \quad$ Published: 11 July 17

\begin{abstract}
Background: The role of decompressive craniectomy in treating raised intracranial pressure (ICP) after traumatic brain injuries (TBI) is controversial. The aim of this study was to assess the differences in prognosis of patients initially treated by decompressive craniectomy, craniotomy, or conservatively.

Methods: We conducted a single-center retrospective study on adult blunt TBI patients admitted to a neurosurgical intensive care unit during 2009-2012. Patients were divided into three groups based on their initial treatment - decompressive craniectomy, craniotomy, and conservative. Primary outcome was 6-month Glasgow Outcome Scale (GOS) dichotomized to favorable outcome (independent) and unfavorable outcome (dependent). The association between initial treatment and outcome was assessed using a logistic regression model adjusting for case-mix using known predictors of outcome.

Results: Of the 822 included patients, 58 patients were in the craniectomy group, 401 patients in the craniotomy group, and 363 patients in the conservatively treated group. Overall, 6-month unfavorable outcome was $48 \%$. After adjusting for case-mix, patients in the decompressive craniectomy group had a statistical significantly higher risk for poor neurological outcome compared to patients in the conservative group (OR 3.06, 95\% $\mathrm{Cl} 1.45-6.42$ ) and craniotomy group (OR 3.61, 95\% Cl 1.74-7.51). Conclusion: In conclusion, patients requiring primary decompressive craniectomy had a higher risk for poor neurological outcome compared to patients undergoing craniotomy or were conservatively treated. It is plausible that the poor prognosis is related to the TBI severity itself rather than the intervention. Further prospective randomized trials are required to establish the role of decompressive craniectomy in the treatment of patients with TBI.
\end{abstract}

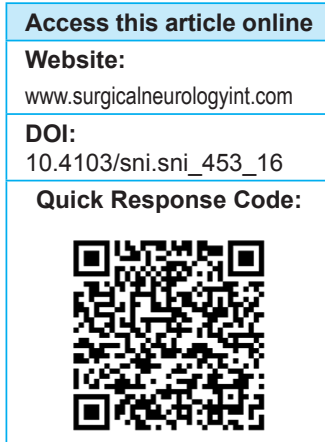

This is an open access article distributed under the terms of the Creative Commons Attribution-NonCommercial-ShareAlike 3.0 License, which allows others to remix, tweak, and build upon the work non-commercially, as long as the author is credited and the new creations are licensed under the identical terms.

For reprints contact: reprints@medknow.com

How to cite this article: Tapper J, Skrifvars MB, Kivisaari R, Siironen J, Raj R. Primary decompressive craniectomy is associated with worse neurological outcome in patients with traumatic brain injury requiring acute surgery. Surg Neurol Int 2017;8:141.

http://surgicalneurologyint.com/Primary-decompressive-craniectomy-is-associated-with-worse-neurological-outcome-in-patients-with-traumatic-brain-injury-requiring-acute-surgery/ 
Key Words: Craniotomy, decompressive craniectomy, mortality neurological outcome, surgery traumatic brain injury

\section{INTRODUCTION}

The choice of acute surgical treatment of patients with traumatic brain injury (TBI) is a controversial subject. Primary decompressive hemicraniectomy is used as the first line surgical therapy in some institutions, whereas smaller craniotomies (with hematoma evacuation) are used in others. ${ }^{[1,2]}$

Raised intracranial pressure levels increases the risk for secondary brain ischemia and is highly correlated with poor outcome, which highlights the importance of aggressive ICP-directed treatment. ${ }^{[3-9]}$ Today it is unknown whether patients requiring acute surgery for raised intracranial pressure should be treated primarily by craniotomy and hematoma evacuation or by decompressive craniectomy. ${ }^{[2,9-13]}$ To date, no clinical trial has shown any benefit of primary decompressive craniectomy in terms of patient outcome, although it is effective in acutely lowering ICP. ${ }^{[1,15]}$ Recently, the RESCUE-ICP trial, which compared conservative management versus decompressive craniectomy for refractory intracranial hypertension, showed lower mortality rates in the craniectomy group, but with higher disabilities at 6 months following injury. ${ }^{[16]}$ Yet, few previous studies have the choice of craniotomy versus craniectomy as a firstline surgical therapy for patients with severe TBI requiring surgery.

The aim of this study was to assess the independent relationship between initial treatment (decompressive craniectomy, craniotomy, or conservative treatment) and patient prognosis in patients with TBI treated in a neurosurgical intensive care unit (ICU).

\section{MATERIALS AND METHODS}

We conducted an open-cohort retrospective study among 822 adult ( $\geq 18$ years) blunt TBI patients admitted to the neurosurgical ICU of Töölö Hospital, University hospital of Helsinki, between January 1, 2009 and December 31, 2012. Töölö hospital is one of the largest trauma 1 hospitals in Northern Europe, covering a population of approximately 2 million people.

Patient data was retrospectively gathered from electronic hospital charts. Patient admission variables were assessed by the treating neurosurgeon and collected from subsequent electronic records. All admission head computerized tomography (CT) scans were classified by two authors (R.R, R.K) ${ }^{[17,18]}$

Patients were divided based on their primary neurosurgical intervention into conservative treatment, acute craniotomy and mass lesion evacuation (craniotomy), and decompressive craniectomy (craniectomy). Patients who first underwent craniotomy and later had to be treated with decompressive craniectomy were classified as decompressive craniectomy patients.

Our primary outcome was 6-month neurological outcome, defined according to the Glasgow Outcome Scale (GOS). We dichotomized neurological outcome to favorable and unfavorable outcomes. Unfavorable outcome was defined as GOS 1 (death), 2 (vegetative state), and 3 (severe disability). Favorable outcome was defined as GOS 4 (moderate disability) and 5 (good recovery). The GOS was assessed based on follow-up visits with a neurosurgeon or neurologist. As a secondary outcome of interest, we used 6-month mortality which was determined from the Finnish population registry (available for all Finnish citizens).

The treatment protocol for patients with severe TBI are based upon the Brain Trauma Foundation's guidelines. ${ }^{[19]}$ In general, patients with operable hematomas without signs of diffuse brain injury and raised ICP are treated by craniotomy and hematoma evacuation. Primary decompressive craniectomy is usually reserved for those with signs of severe intracranial hypertension on the admission head CT (e.g., obliterated basal cisterns, diffuse bilateral swelling, or midline shift non-proportional to the size of the hematoma).

\section{Statistical methods}

Categorical variables are presented as $N(\%)$ and tested using a two-sided Chi-square test. Continuous data were tested for skewness - normally distributed data are presented as mean (SD) and skewed data as median (IQR). Normally distributed data are tested using a $t$-test and skewed data are tested using the Mann-Whitney $U$ test. To test the independent effect of decompressive craniectomy on outcome, we created a binary logistic regression model adjusting for factors previously known to predict outcome after TBI. The included covariates were age, the Glasgow Coma Scale (GCS) motor score, pupillary light reactivity, hypoxia, hypotension, hemoglobin, glucose, and the Helsinki CT score. ${ }^{[15,18]}$ The results from the logistic regression model are presented as odds ratios (OR) with 95\% confidence intervals (CI).

\section{RESULTS}

Of the 822 included patients, 401 underwent craniotomy (49\%), 58 craniectomy (7\%), and 363 patients (44\%) did not require surgery (conservative group). Table 1 shows study baseline characteristics. The patients forming the 
Table 1: Study population baseline characteristics

\begin{tabular}{|c|c|c|c|c|}
\hline Variables & $\begin{array}{c}\text { No operation } \\
n=363\end{array}$ & $\begin{array}{c}\text { Craniotomy } \\
n=401\end{array}$ & $\begin{array}{c}\text { Craniectomy } \\
\quad n=58\end{array}$ & $P$ \\
\hline Age & $57(42-67)$ & $61(50-71)$ & $45(29-55)$ & $<0.001$ \\
\hline \multicolumn{5}{|l|}{ GCS } \\
\hline 3-8 & $133(36.6 \%)$ & $183(45.6 \%)$ & $42(72.4 \%)$ & \multirow[t]{3}{*}{$<0.001$} \\
\hline $9-12$ & $83(22.9 \%)$ & $100(24.9 \%)$ & $13(22.4 \%)$ & \\
\hline $13-15$ & $147(40.5 \%)$ & 118 (29.4\%) & $3(5.2 \%)$ & \\
\hline \multicolumn{5}{|l|}{ Motor score } \\
\hline None/extension & $68(18.7 \%)$ & $85(21.2 \%)$ & $23(39.7 \%)$ & \multirow[t]{3}{*}{$<0.001$} \\
\hline Normal/abnormal flexion & $39(10.7 \%)$ & $70(17.5 \%)$ & $11(19.0 \%)$ & \\
\hline Localizes/obeys & $256(70.5 \%)$ & $246(61.3 \%)$ & $24(41.4 \%)$ & \\
\hline \multicolumn{5}{|l|}{ Pupillary light reactivity } \\
\hline None & $63(17.4 \%)$ & $52(13.0 \%)$ & $7(12.1 \%)$ & \multirow[t]{3}{*}{$<0.001$} \\
\hline One & $17(4.7 \%)$ & $66(16.5 \%)$ & $11(19.0 \%)$ & \\
\hline Both & $283(78.0 \%)$ & $283(70.6 \%)$ & $40(69.0 \%)$ & \\
\hline Hypoxia & $66(18.2 \%)$ & $48(12.0 \%)$ & $13(22.4 \%)$ & 0.019 \\
\hline Hypotension & $36(9.9 \%)$ & $22(5.5 \%)$ & $4(6.9 \%)$ & 0.067 \\
\hline Midline shift (mm) & $0(0-4)$ & $9(4-14)$ & $4(0-11)$ & $<0.001$ \\
\hline \multicolumn{5}{|l|}{ Basal cisterns } \\
\hline Normal & $273(75 \%)$ & $160(40 \%)$ & $18(31 \%)$ & \multirow[t]{2}{*}{$<0.001$} \\
\hline Compressed or obliterated & $90(25 \%)$ & $241(60 \%)$ & $40(69 \%)$ & \\
\hline \multicolumn{5}{|l|}{ Marshall CT } \\
\hline$\|$ & $216(59.5 \%)$ & $42(10.5 \%)$ & $10(17.2 \%)$ & \multirow[t]{4}{*}{$<0.001$} \\
\hline III & $22(6.1 \%)$ & $4(1.0 \%)$ & $10(17.2 \%)$ & \\
\hline IV & $14(3.9 \%)$ & $11(2.7 \%)$ & $5(8.6 \%)$ & \\
\hline EML/NEML & $111(30.6 \%)$ & $344(85.8 \%)$ & $33(56.9 \%)$ & \\
\hline \multicolumn{5}{|l|}{ Rotterdam } \\
\hline 1 & $15(4.1 \%)$ & $13(3.2 \%)$ & $0(0.0 \%)$ & \multirow[t]{6}{*}{$<0.001$} \\
\hline 2 & $76(20.9 \%)$ & $52(13.0 \%)$ & $1(1.7 \%)$ & \\
\hline 3 & $183(50.4 \%)$ & $90(22.4 \%)$ & $15(25.9 \%)$ & \\
\hline 4 & $35(9.6 \%)$ & $116(28.6 \%)$ & $18(31.0 \%)$ & \\
\hline 5 & $34(9.4 \%)$ & $97(24.2 \%)$ & $15(25.9 \%)$ & \\
\hline 6 & $20(5.5 \%)$ & $33(8.2 \%)$ & $9(15.5 \%)$ & \\
\hline Helsinki CT score $(I Q R)$ & $4(2-6)$ & $5(4-7)$ & $6(4-8.25)$ & $<0.001$ \\
\hline Glucose mmol/l & $7.2(6.2-8.7)$ & $7.2(5.9-8.8)$ & $7.6(6.7-9.4)$ & 0.058 \\
\hline Hemoglobin $(\mathrm{g} / \mathrm{L})$ & $130(116.0-142.0)$ & $121(109.0-134.0)$ & $129(117.0-138.0)$ & $<0.001$ \\
\hline \multicolumn{5}{|l|}{ Length of stay } \\
\hline ICU & $1.8(1.0-4.0)$ & $2.5(1.0-5.6)$ & $11(5.4-15.6)$ & $<0.001$ \\
\hline Hospital & $7(3.0-11.0)$ & $8(4.0-15.0)$ & $18(12.0-25.0)$ & $<0.001$ \\
\hline \multicolumn{5}{|l|}{ Six month outcome } \\
\hline Unfavourable outcome & $148(40.8 \%)$ & $214(53.4 \%)$ & $35(60.3 \%)$ & $<0.001$ \\
\hline Mortality & $85(23.4 \%)$ & $107(26.7 \%)$ & $16(27.6 \%)$ & 0.536 \\
\hline
\end{tabular}

Abbreviations: GCS: Glasgow Coma Scale, ICU: Intensive Care Unit

decompressive craniectomy group were significantly younger (median 45 years, IQR 29-55) than the two other study groups [median 6l years (IQR 50-71) for craniotomy and median 57 years (42-67) for conservative group, $<0.001]$.

The majority of patients (72\%) who underwent decompressive craniectomy had GCS score of 8 or lower, whereas these patients were significantly less frequent in the craniotomy and conservative groups (46\% and $37 \%, P<0.001)$. An abnormal pupillary light reaction was significantly more frequent in the decompressive craniectomy group compared to the craniotomy and conservative groups $(31 \%, 29 \%$, and $22 \%$, respectively; $P<0.001)$.

Patients in the decompressive craniectomy group (4 mm, IQR 0-ll) and patients in the craniotomy 
group (9 mm, IQR 4-14) had significantly more midline shift on their primary head-CT scan than patients in the conservative group $(0 \mathrm{~mm}$, IQR $0-4)(<0.001)$. Of patients in the decompressive craniectomy group, 69\% had compressed or obliterated basal cisterns on their admission head-CT scan compared to $60 \%$ and $25 \%$ in the craniotomy and conservative groups, respectively. Further, the median Helsinki CT score was significantly higher in the decompressive craniectomy group compared to the craniotomy and conservative groups (median score 6 out of 14 vs. 5 out of 14 and 4 out of 14, respectively).

\section{Unadjusted outcome}

Regarding outcome, $60 \%$ of the patients in the decompressive craniectomy group had an unfavorable outcome compared to $53 \%$ and $41 \%$ in the craniotomy and conservatively treated groups, respectively $(P<0.001)$. There were, however, no significant difference in unadjusted 6-month mortality rate between the groups (range $23-28 \%, P=0.536$ ).

\section{Multivariate analysis}

Results from the multivariate logistic regression analysis is shown in Table 2. Higher age was highly associated with a higher risk for unfavorable outcome (OR 1.06, 95\% CI 1.051.07 ) and 6-month mortality (OR 1.06, 95\% CI 1.05-1.08). The number of reactive pupils had an inverse correlation with poor outcome. The GCS motor score, Helsinki CT score, and admission hemoglobin levels strongly associated with 6-month outcome, as well [Table 2].

For 6-month unfavorable neurological outcome, patients in the decompressive craniectomy group had a 3.06
(95\% CI 1.45-6.42, P < 0.001) higher odds for unfavorable neurological outcome compared to conservatively treated patients and a 3.61 (95\% CI 1.74-7.51, $P<0.001$ ) higher odds compared to patients in the craniotomy group [Figure 1]. For 6-month mortality, decompressive craniectomy was not associated with an increased risk for death (OR 1.73, 95\% CI 0.75-4.01, $P=0.199$ ) compared to conservatively treated patients but was associated with an increased risk for death compared to patients in the craniotomy group (OR 2.47, 95\% CI 1.10-5.55, P = 0.029).

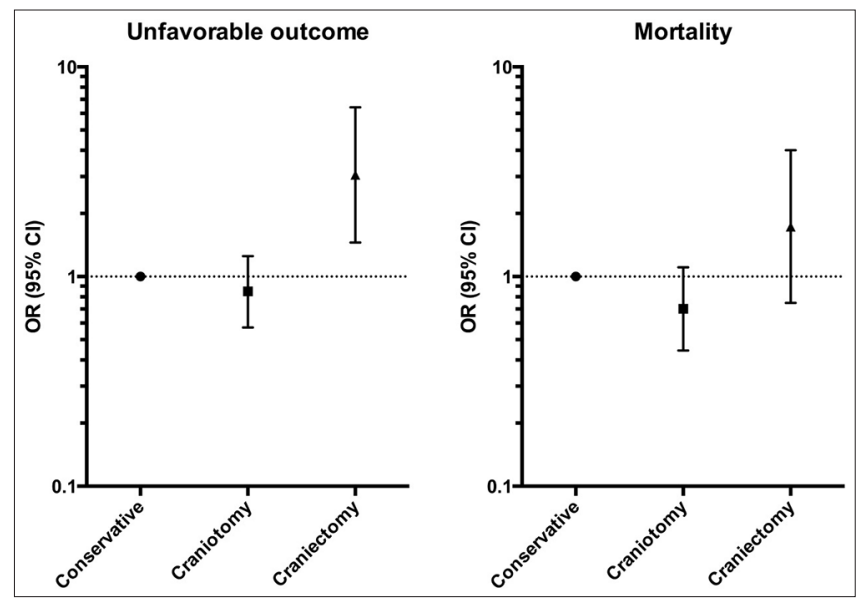

Figure I: Results from the multivariate analysis. To the left the independent effect of primary operation technique on six-month mortality and to the right the effect on six-month unfavorable outcome. Decompressive craniectomy was independently associated with an increased risk for unfavorable neurological outcome but not mortality. Abbreviations: OR, Odds Ratio; $\mathrm{Cl}$, Confidence Intervals

\section{Table 2: Results from the multivariate analysis}

\begin{tabular}{|c|c|c|c|c|}
\hline \multirow[t]{2}{*}{ Variables } & \multicolumn{2}{|c|}{ Unfavorable outcome } & \multicolumn{2}{|c|}{ Mortality } \\
\hline & Odds ratio (95\% Cl) & $\boldsymbol{P}$ & Odds ratio (95\% CI) & $P$ \\
\hline Age & $1.06(1.05-1.07)$ & $<0.001$ & $1.06(1.05-1.08)$ & $<0.001$ \\
\hline \multicolumn{5}{|l|}{ Pupil reactivity } \\
\hline None & & 0.006 & & $<0.001$ \\
\hline One & $0.50(0.23-1.08)$ & 0.078 & $0.30(0.15-0.59)$ & $<0.001$ \\
\hline Both & $0.34(0.17-0.67)$ & $<0.001$ & $0.19(0.10-0.36)$ & $<0.001$ \\
\hline \multicolumn{5}{|l|}{ Motor score } \\
\hline None/extension & & $<0.001$ & & $<0.001$ \\
\hline Normal/abnormal flexion & $0.54(0.29-1.04)$ & 0.065 & $0.57(0.31-1.07)$ & 0.081 \\
\hline Localizes/obeys & $0.31(0.17-0.55)$ & $<0.001$ & $0.33(0.18-0.60)$ & $<0.001$ \\
\hline Glucose & $0.99(0.92-1.07)$ & 0.878 & $1.11(1.03-1.20)$ & 0.008 \\
\hline Hemoglobin & $0.98(0.97-0.99)$ & $<0.001$ & $0.98(0.97-0.99)$ & $<0.001$ \\
\hline Hypoxia & $1.52(0.91-2.53)$ & 0.107 & $1.48(0.87-2.51)$ & 0.148 \\
\hline Hypotension & $0.79(0.37-1.69)$ & 0.548 & $1.04(0.47-2.32)$ & 0.917 \\
\hline \multicolumn{5}{|l|}{ Operation } \\
\hline No operation & & 0.003 & & 0.052 \\
\hline Craniotomy & $0.85(0.57-1.25)$ & 0.401 & $0.70(0.44-1.11)$ & 0.128 \\
\hline Decompressive craniectomy & $3.06(1.45-6.42)$ & $<0.001$ & $1.73(0.75-4.01)$ & 0.199 \\
\hline Helsinki CT score & $1.21(1.13-1.29)$ & $<0.001$ & $1.18(1.10-1.30)$ & $<0.001$ \\
\hline
\end{tabular}




\section{DISCUSSION}

\section{Key findings}

In this study, we investigated the association between decompressive craniectomy versus craniotomy and outcome, as the first line surgical treatment, in patients with TBI treated in the ICU requiring acute surgery. As a control group we used patients conservatively treated in the ICU. We examined unfavorable neurological outcome and mortality and found that decompressive craniectomy was associated with a higher risk for unfavorable outcome and mortality compared to patients undergoing craniotomy. Our study is retrospective and, thus, one should be careful to draw any far going conclusions regarding the application of decompressive craniectomy based on our results. We highlight that the purpose of the study was not to assess the effectiveness of decompressive craniectomy but rather to assess the differences in outcome between patients undergoing decompressive craniectomy and craniotomy as the firstline surgical treatment.

Our results should not be surprising as decompressive craniectomy is often reserved to presenting with signs of severe intracranial hypertension who have the poorest baseline prognosis. This is supported by our study as patients in the craniectomy group more frequently displayed abnormal basal cisterns, lower GCS scores, and abnormal pupils than patients in the craniotomy group. Thus, it is plausible that the TBI severity in itself is the major determinant of patient outcome, regardless of the surgical technique performed (craniotomy or decompressive craniectomy). There is, however, a possibility that craniectomy allowed some of the most severe TBI patients to survive at the cost of neurological function, something that should be considered before performing the surgery.

Noteworthy, patients in the craniotomy group had a higher degree of midline shift but less compression of the basal cisterns than patients in the craniectomy group, indicating removable mass lesions in the craniotomy group and more diffuse swelling in the craniectomy group. The fact that craniotomy was not associated with an increased risk for poor outcome compared to conservatively treated patients that these patients' prognosis can be improved through adequate mass lesion evacuation.

\section{Previous studies}

Decompressive craniectomy has for long been one of the most controversial topics in neurotrauma. Some studies have addressed this matter by presenting somewhat similar

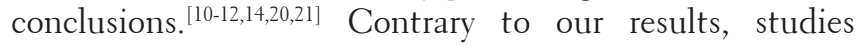
report no significant difference in outcome between the two operations. ${ }^{[10-13]}$ It is also shown that decompressive craniectomy accounts for higher mortality. ${ }^{[12,13,20-22]}$ It is also suggested that the role of the operation type is irrelevant. ${ }^{[11,23]}$ The results of our study finds some support in previously conducted research where the outcome of decompressive craniectomy is poorer than for the rest. ${ }^{[24,25]}$ Regarding outcome, decompressive craniectomy has been determined the worse option of the two operations, which also aligns with our results. ${ }^{[2,26]}$

Almost without exception, the conducted studies are of retrospective nature and some lack proper randomization $^{[10,26]}$ and thus, cannot provide us the most reliable results we need. Recently, the RESCUE-ICP study was published. ${ }^{[16]}$ In the study, decompressive craniectomy was compared to maximal conservative treatment for patients with refractory intracranial hypertension, and not primary surgery, as in the current study. Yet, the RESCUE-ICP results align with the results provided by our study. Both studies showed a higher risk for poor neurological outcome in patients undergoing decompressive craniectomy. This supports the results of our study, which highlights a similar trend in outcome. The recently started RESCUE-ASDH trial aim to compare primary decompressive craniectomy and craniotomy. The study will give us the best evidence till date regarding the preferred surgical technique. Until then, our present study is one of the largest retrospective surgical series presented on this topic.

\section{Limitations}

There are a few limitations to our study that should be discussed. First, the study was of retrospective nature, which meant that case-mix differences between the decompressive craniectomy, craniotomy, and conservatively treated group are unavoidable. We accounted for some case-mix differences by applying a logistic regression model adjusting for the previously known predictors of outcome after TBI. However, such case-mix adjustment is only as good as the model used and variables not included are not adjusted for. It should be stressed that the aim of this study was not to assess the effectiveness of decompressive craniectomy but to assess the association between the need for decompressive craniectomy as the primary surgery and outcome. Second, this was a single-center study, which means that broader one should be careful to generalize our results. Our institution is, however, of the largest trauma units in Northern Europe, covering almost 2 million people and, thus, represent a large portion of severe TBI cases in Europe. Third, as a primary outcome of interest we used neurological outcome, defined by the GOS. The GOS does not account for important aspects of recovery after TBI such as patient quality of life and neuropsychological outcome.

\section{CONCLUSION}

Patients requiring primary decompressive craniectomy had a higher risk for poor neurological outcome and mortality compared to patients undergoing craniotomy. It is plausible that the poor prognosis is related to the TBI severity itself rather than to the intervention. Further 
prospective randomized trials are required to establish the role of decompressive craniectomy in the treatment of patients with TBI.

\section{Financial support and sponsorship \\ Nil.}

\section{Conflicts of interest}

There are no conflicts of interest.

\section{REFERENCES}

I. Kolias AG, Belli A, Li LM, Timofeev I, Corteen EA, Santarius T, et al. Primary decompressive craniectomy for acute subdural haematomas: Results of an international survey. Acta Neurochir 2012;154:1563-5.

2. Kolias AG, Scotton WJ, Belli A, King AT, Brennan PM, Bulters DO, et al. Surgical management of acute subdural haematomas: Current practice patterns in the United Kingdom and the Republic of Ireland. Br J Neurosurg 2013;27:330-3.

3. Ghajar J. Traumatic brain injury. Lancet 2000;356:923-9.

4. Aarabi B, Hesdorffer DC, Ahn ES, Aresco C, Scalea TM, Eisenberg HM. Outcome following decompressive craniectomy for malignant swelling due to severe head injury. J Neurosurg 2006; 104:469-79.

5. Bullock R, Chesnut R, Clifton G, Ghajar J, Marion D, Narayan R, et al. Guidelines for the management of severe head injury. Eur J Emerg Med 1996;3:109-27.

6. Maas Al, Stocchetti N, Bullock R. Moderate and severe traumatic brain injury in adults. Lancet Neurol 2008;7:728-4I.

7. Oshorov AV, Popugaev KA, Savin IA, Lubnin AY. [The use of intravascular hypothermia to correct intracranial hypertension in patients with severe traumatic brain injury]. Zh Vopr Neirokhir Im N N Burdenko 20 I 4;78:4I-7.

8. Servadei F, Compagnone C, Sahuquillo J. The role of surgery in traumatic brain injury. Curr Opin Crit Care 2007;13:163-8.

9. Stocchetti N. Traumatic brain injury: Problems and opportunities. Lancet Neurol 2014;13:14-6.

10. Coplin WM, Cullen NK, Policherla PN, Vinas FC. Safety and feasibility of craniectomy with duraplasty as the initial surgical intervention for severe traumatic brain injury. J Trauma 2001;50:1050-9.

II. Li LM, Kolias AG, Guilfoyle MR, Timofeev I. Outcome following evacuation of acute subdural haematomas: A comparison of craniotomy with decompressive craniectomy. Acta Neurochir 2012;154:1555-6I.

12. Paci GM, Sise MJ, Sise CB, Sise CB, Sack DI, Sack DI, et al. Preemptive craniectomy with craniotomy: What role in the management of severe traumatic brain injury? J Trauma 2009;67:531-6.

13. Woertgen C, Rothoerl RD, Schebesch KM, Albert R. Comparison of craniotomy and craniectomy in patients with acute subdural haematoma. J Clin Neurosci 2006; 13:7|8-2I.

14. Cooper DJ, Rosenfeld JV, Murray L, Arabi YM, Davies AR, D'Urso P, et al. Decompressive Craniectomy in Diffuse Traumatic Brain Injury. N Engl J Med 201 I;364:1493-502.

15. Kunze E, Meixensberger J, Janka M, Sorensen N. Decompressive craniectomy in patients with uncontrollable intracranial hypertension. Acta Neurochir 1998;7::16-8.

16. Shutter LA, Timmons SD. Intracranial Pressure Rescued by Decompressive Surgery after Traumatic Brain Injury. N Engl J Med 2016;375:I I83-84.

17. Murray GD, Butcher I, McHugh GS, Lu J. Multivariable prognostic analysis in traumatic brain injury: Results from the IMPACT study. J Neurotrauma 2007;24:329-37.

18. Raj R, Siironen J, Skrifvars MB, Hernesniemi J. Predicting outcome in traumatic brain injury: development of a novel computerized tomography classification system (Helsinki computerized tomography score). Neurosurgery 2014;75:632-46.

19. Brain Trauma Foundation, American Association of Neurological Surgeons, Congress of Neurological Surgeons. Guidelines for the management of severe traumatic brain injury. J Neurotrauma 2007;24(Suppl I):i-vi.

20. Chen SH, Chen Y, Fang W, Fang WK, Huang D, Huang DW, et al. Comparison of craniotomy and decompressive craniectomy in severely head-injured patients with acute subdural hematoma. J Trauma 201 I;71:1632-6.

21. Schneider GH, Bardt T, Lanksch WR, Unterberg A. Decompressive craniectomy following traumatic brain injury: ICP, CPP and neurological outcome. Acta Neurochir Suppl 2002;81:77-9.

22. Rush B, Rousseau J, Sekhon MS, Griesdale DE. Craniotomy Versus Craniectomy for Acute Traumatic Subdural Hematoma in the United States: A National Retrospective Cohort Analysis. World Neurosurg 2016;88:25-3I.

23. Sahuquillo J, Arikan F. Decompressive craniectomy for the treatment of refractory high intracranial pressure in traumatic brain injury. Cochrane Database Syst Rev 2006; 1:CD003983.

24. Kim KH. Predictors for functional recovery and mortality of surgically treated traumatic acute subdural hematomas in 256 patients. J Korean Neurosurg Soc 2009;45: 143-50.

25. Skoglund TS, Eriksson-Ritzén C, Jensen C, Rydenhag B. Aspects on decompressive craniectomy in patients with traumatic head injuries. J Neurotrauma 2006;23:1502-9.

26. Stein SC, Georgoff P, Meghan S, Mirza KL, El Falaky OM. Relationship of aggressive monitoring and treatment to improved outcomes in severe traumatic brain injury. J Neurosurg 2010; I 2: I 105-12.

\section{Commentaries}

\section{Decompressive craniectomy in the treatment of severe traumatic brain injury: The question of quality of survival}

In this article, Tapper, et al. detail their considerable experience in the treatment of adults with severe traumatic brain injury (TBI) over a four year period. The geography and local health care system overseen by their home institution provide for an outstanding representative example of this disease process. Advantages of this study include the consistent protocol driven care at a single center of excellence, the extremely high volume of patients cared for over this time period, and the rigorousness of the authors' data collection methodology and statistical analysis. Disadvantages of this study include its retrospective, non-blinded, non-randomized, non-variable adjusted control and comparison groups. Out of the 822 patients seen over this time period that met the study's inclusion criteria, 401 or over 7 times as many patients had a standard craniotomy and lesion evacuation as had a decompressive craniectomy. This discrepancy reflects the authors' operative protocol to restrict decompresive craniectomy to only those patients with the most severe evidence of preoperative intracranial hypertension. 363 or over $40 \%$ of the patients 
were treated non-operatively (had no operative lesion or evidence of severe intracranial hypertension on admission imaging). Clearly, decompressive craniectomy, as others have also shown, ${ }^{[1-5]}$ is a powerful tool to acutely lower intracranial hypertension. This is reinforced here as the 6 month mortality of $27.6 \%$ in the decompressive craniectomy group is not statistically different from the mortality of the standard craniotomy and non-operative treatment groups, despite the more dire circumstances in which these patients initially presented. However, as previously revealed in the more powerful, although not equivalent, RESCUEicp trial, ${ }^{[6]}$ the authors discovered that survival in general did not translate specifically into a favorable (independent) outcome. Only $40 \%$ of decompressive craniectomy patients achieved GOS score $4-5$ at 6 months post injury versus almost $50 \%$ of standard craniotomy and almost $60 \%$ of non-operative patients. But despite the title of the authors' manuscript, given the non-randomized nature of the treatment groups, it would be inappropriate to definitively conclude that standard craniotomy leads to better outcomes than decompressive craniectomy any more than it would be to conclude that non-operative treatment leads to better outcomes than standard craniotomy in the treatment of severe TBI. This study does, however, provide more evidence as to the complicated nature of quantifying a successful outcome in patients undergoing decompressive craniectomy and temper some of the enthusiasm associated with this procedure. As the authors suggest, we await the results of the ongoing RESCUE-ASDH trial ${ }^{[7]}$ to help us better clarify the debate as to the indications and expected outcomes of decompressive craniectomy in the treatment of severe TBI.

\author{
Hal S. Meltzer, Cecilia L. Dalle Ore \\ University of California at San Diego, San Diego, CA, USA \\ E-mail: hsmeltzer@ucsd.edu, cdalleor@ad.ucsd.edu
}

\section{REFERENCES}

I. Aarabi B, Hesdorffer DC, Ahn ES, Aresco C, Scalea TM, Eisenberg HM. Outcome following decompressive craniectomy for malignant swelling due to severe head injury. J Neurosurg 2006; 104:469-79.

2. Albanèse J, Leone M, Alliez JR, Kaya JM, Antonini F, Alliez B, et al. Decompressive craniectomy for severe traumatic brain injury: Evaluation of the effect at one year. Crit Care Med 2003;31:2535-8.

3. Cooper DJ, Rosenfeld JV, Murray L, Arabi YM, Davies AR, D'Urso P, et al. Decompressive craniectomy in diffuse traumatic brain injury. $\mathrm{N}$ Engl J Med 20II;364:1493-502.

4. Howard JL, Cipolle MD, Anderson M, Sabella V, Shollenberger D, Li PM, et al. Outcome after decompressive craniectomy for the treatment of severe traumatic brain injury. J Trauma 2008;65:380-5.

5. Olivecrona M, Rodling-Wahlström M, Naredi S, Koskinen LO. Effective ICP reduction by decompressive craniectomy in patients with severe traumatic brain injury treated by an ICP-targeted therapy. J Neurotrama 2007;24:927-35.

6. Hutchinson PJ, Kolias AG, Timofeev IS, Corteen EA, Czosnyka M, Timothy J, et al. Trial of decompressive craniectomy for traumatic intracranial hypertension. N Engl J Med 2016;375: I I 19-30.

7. Kolias AG, Adams H, Timofeev I, Czosnyka M, Corteen EA, Pickard JD, et al. Decompressive craniectomy following traumatic brain injury: Developing the evidence base. Br J Neurosurg 2016;30:246-50.

\section{Comment on results of decompressive craniotomy for trauma}

The authors of "Primary decompressive craniectomy is associated with worse neurological outcome in patients with traumatic brain injury requiring acute surgery" present a large single center series of neurotrauma patients who were treated by craniotomy, craniotomy, or nonsurgical means.

The question of the efficacy of craniotomy as a treatment for various neurological injuries associated with secondary brain swelling is an important topic, and the subject of much current discussion.

The question is ripe from both technical and philosophical/ ethical perspectives. The technical question is "does the treatment lead to an improved neurological outcome?" The related ethical question is "what do we mean by an improved outcome?" In statistics, the "binning" of data points is an irreducible aspect of the analysis itself. The choice of the grouping borderline between satisfactory and unsatisfactory outcomes is therefore of necessary interest, and honorable opinions can vary regarding these definitions. The authors present this dilemma.

Attempts were made to adjust for case mix, but "Patients who first underwent craniotomy and later had to be treated with decompressive craniectomy were classified as decompressive craniectomy patients," a comment that shrieks out for further subanalysis. Moreover, the timing of GCS relative to timing of intervention is a significant, and unanswered, question. The authors appropriately note the difficulties inherent in statistical analysis, and the limits of their post-hoc, but necessarily imperfect, attempts to adjust for these difficulties.

The authors present their results, which suggest that craniectomy is not helpful in cases of traumatic brain injury, compared to craniotomy or maximal medical therapy.

Their conclusion that "It is plausible that the poorer prognosis is related to the TBI severity itself rather than to the intervention. Further prospective randomized trials are required to establish the role of decompressive craniectomy in the treatment of patients with TBI," 
is well supported, though the social costs of such C. David Hunt randomized control trials may be impossible to pay. They are to be congratulated for illuminating a few data points related to this intractable problem.

Marquette General Neurosurgery; Brooklyn, NY, USA E-mail: davidhunt@mac.com 